\title{
Perfil cromático de embalagens de produtos lácteos - um estudo preliminar
}

\author{
Color profile of dairy products packaging - a preliminary analysis
}

David Guilhon, Erika V. de Castro, Viviane P. da Silva

cor, design, embalagens, laticínios

A cor é um fenômeno muito importante na vida humana, sobre os vários aspectos. É mediadora de sensações e sentimentos, promovendo pontes entre valores e produtos de consumo, em especial os produtos lácteos, alvo desta pesquisa, importantes tanto na economia, quanto na nutrição. O artigo visa analisar amostras de leite em pó, leite líquido, leite condensado e creme de leite encontrados no comércio varejista da cidade de São Luís do Maranhão. A metodologia aplicada pautou-se em 4 fases: identificação das marcas dos fabricantes, mapeamento e seleção das variáveis, coleta das cores e a montagem do perfil de cores. Os resultados mais relevantes então encontrados mostram a predominância do branco $(38,45 \%)$ como cor principal e como secundária, seguido pelos tons de azuis $(34,62 \%)$, igualmente enquadrados. A literatura sugere que tais cores, além de adequadas à produtos alimentícios e lácteos, asseguram ao consumidor qualidade, pureza, tranquilidade, confiança e verdade no que é vendido. Cores como vermelho $(11,54 \%)$ e amarelo $(7,69 \%)$, levantam a hipótese de a necessidade específica de marca e/ou linha de produto buscar destacar-se dos concorrentes. Conclui-se, ainda, que são necessários estudos mais aprofundados, ampliando a quantidade de marcas, como uma investigação focada em só um tipo de produto.

color, design, packaging, dairy

Color is a very important phenomenon in human life, on the various aspects. It is a mediator of sensations and feelings, being an interlocutor between values and consumer products, especially dairy products, a key point of this research, important both in the economy and in nutrition. The article aims to evaluate samples of powdered milk, liquid milk, condensed milk and cream found in retail stores in the city of São Luís do Maranhão. The methodology used was based on 4 stages: identification of the manufacturers' brands, mapping and selection of variables, collection of colors and the assembly of the color profile. The most relevant results found show the hegemony of white (38.45\%) as the main and secondary color, followed by the blue tones (34.62\%), which are also framed. Literature proposes that such colors, in addition to being suitable for food and dairy products, assure consumers of quality, purity, tranquility, confidence and truth in what is sold. Colors such as red (11.54\%) and yellow (7.69\%), raise the hypothesis that the specific need for a brand and / or product line seeks to stand out from competitors. It is also concluded that more in-depth studies are needed, expanding the number of brands, as an investigation focused on only one type of product.

Anais do $10^{\circ} \mathrm{CIDI}$ e $10^{\circ} \mathrm{CONGIC}$

Kelli C.A.S. Smythe, Rafael de Castro Andrade (orgs.)

Sociedade Brasileira de Design da Informação - SBDI

Curitiba | Brasil | 2021
Proceedings of the $10^{\text {th }} \mathrm{CIDI}$ and $10^{\text {th }}$ CONGIC

Kelli C.A.S. Smythe, Rafael de Castro Andrade (orgs.)

Sociedade Brasileira de Design da Informação - SBDI Curitiba | Brazil | 2021 


\section{Introdução}

A cor é muito importante na vida do homem. Está presente de diversas maneiras e em todos os lugares, natural ou artificialmente criadas. Para Farina, Perez e Bastos (2006), é uma realidade sensorial da qual não se pode fugir. E os autores continuam o seu discurso apresentando-a como uma mediadora de sensações e sentimentos.

De fato, não existe cor desprovida de significado, como afirma Heller (2013), pois, cada contexto em que está inserida ela pode propor um valor e um sentido, dada a maneira como se é percebida. O seu significado é também constituído no que Pereira (2011) trata como uma linguagem cromática, constituída de um sistema, dotado de unidades simples (matizes, intensidade e níveis de claridade), enveredando-se por unidades mais complexas (cores e combinações de cores). A autora pressupõe que o sistema define o que o arranjo mais elaborado significa, tal qual um idioma falado.

A cor é um relevante elemento comunicativo (Farina, Perez \& Bastos, 2006) e uma das características mais potentes do design de embalagem de produto na indústria de alimentos (Deliza, Macfie \& Hedderley, 2003). Pois, para Mestriner (2002), Kauppinen-Räisänen (2014) e Mohebbi (2014), ela provoca estímulos visuais e sensoriais, influenciando no comportamento e tomadas de decisão em compras. O exemplo disso são as embalagens de produtos alimentícios que, de acordo com Chiachiri (2011), traz o design de embalagens como o responsável pela primeira impressão que o cliente tem, fornecendo significados, estabelecendo vínculos, já que vão além da função principal de conservar o alimento (Sousa, Carvalho \& Pereira, 2020). Assim, a cor é um dos atributos visuais mais poderosos da embalagem, pois atinge os consumidores em nível mais profundo que o causado pela primeira impressão, sendo usadas por estes para inferências sobre a qualidade dos produtos embalados e seus significados (Deliza, Macfie \& Hedderley, 2003; Kauppinen-Räisänen, 2014).

É em cima dessa "[...] função mágica de atrair o comprador [...]" (Battistela, Colombo \& Abreu, 2010, p.10) que a cor em embalagens de produtos lácteos, objeto deste estudo, aponta algumas conexões entre o produto e consumidor por meio de suas paletas, não sendo meramente decorativas, como fala Silva (2012). Assim, Mestriner (2005) conclui mostrando algumas relações como o uso de azul e branco para embalagens de açúcar, acrescendo vermelho como secundária para leite líquido, ou vermelho e amarelo, além de verde como secundária para leite em pó.

Destarte, tal importância deve ser observada, especialmente em embalagens do setor dos laticínios, não só pelo fato de o leite e seus derivados estarem na dieta humana a décadas de milênios (Benevides \& Veiga, 2014) e ser até hoje seu consumo essencial por conta de seus nutrientes (Jung \& Matte Júnior, 2017; SBAN, 2015), mas, sobretudo tendo em vista a relevância que tal indústria representa para a economia não só nacional. Jung e Matte Júnior (2017) apresentam o Brasil como o quinto maior produtor de leite no mundo, ultrapassando em 2016 a marca de 35 bilhões de litros de leite (Vilela et al., 2016).

Observando a variedades de produtos e marcas nas prateleiras de supermercados e varejos de bairro, percebe-se a presença de uma tendência de cores, dentre um leque bem 
variado, voltadas para segmentos de cada tipo de produto que precisam ser estudados, verificados e documentados

Diante do exposto, este artigo propõe a investigação em caráter preliminar do perfil de cores das embalagens de leite em pó, leite líquido, leite condensado e creme de leite das principais marcas vendidas na rede varejista da cidade de São Luís do Maranhão.

\section{Metodologia do trabalho}

Apoiado no pensamento de Baxter (2011) que ressalta que "o planejamento do produto começa com a estratégia de desenvolvimento de produto" (p. 168).

Figura 1: Infográfico da metodologia utilizado na pesquisa

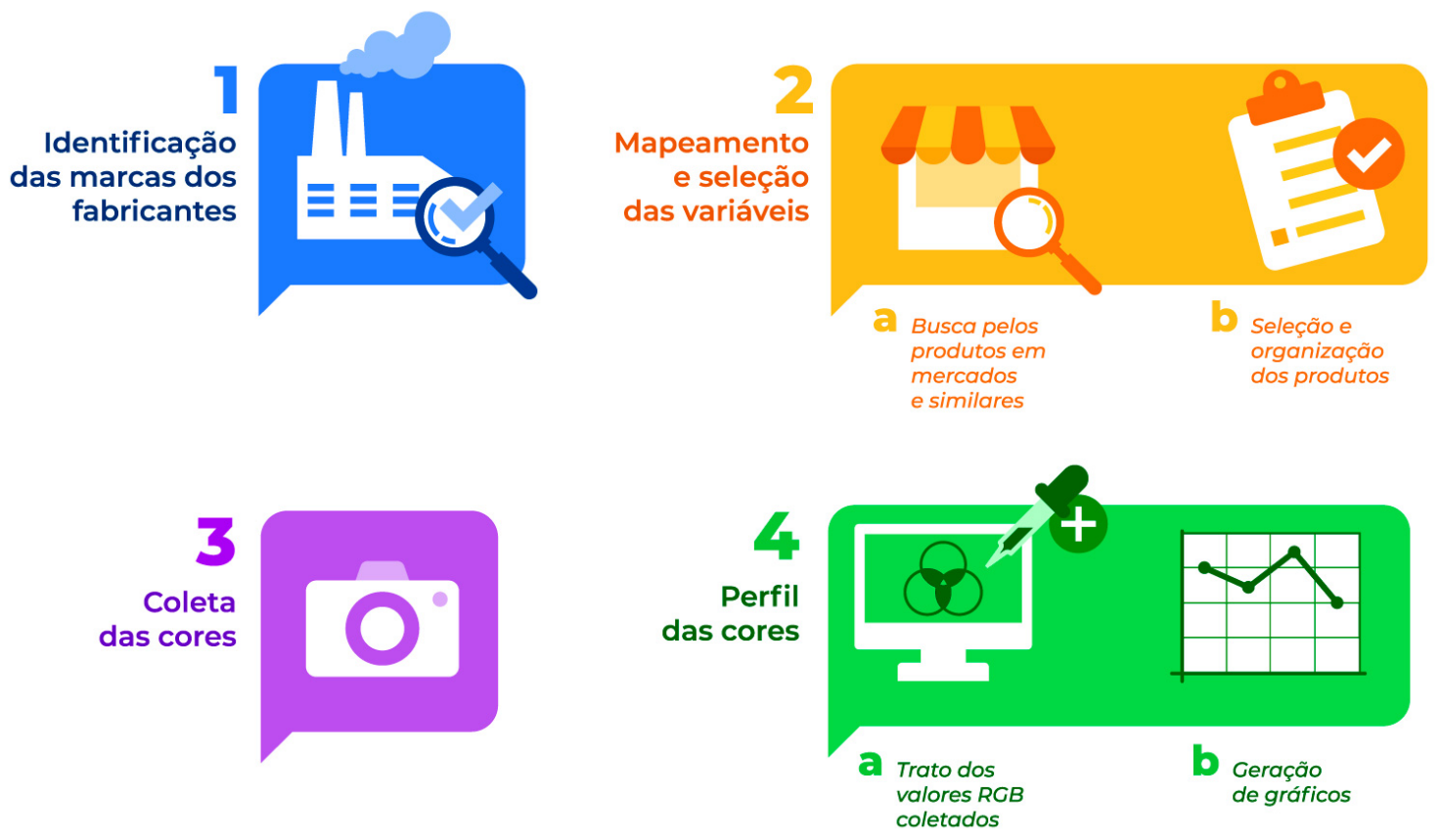

Sendo assim, a figura 1 ilustra o passo a passo de como este estudo é dividido em 4 momentos: 1) Identificação das marcas dos fabricantes; 2) Mapeamento das variáveis e aquisição das amostras; 3) Coleta das cores e; 4) Perfil das cores.

\section{Identificação das marcas dos fabricantes}

Nessa fase fez-se o conhecimento prévio dos produtos a serem avaliados. Adotou-se como parâmetro de seleção das marcas dos produtos uma lista das 4 empresas mais atuantes no ramo lácteo no país (EMBRAPA, 2019), verificando a presença de seus produtos (leite em pó, leite líquido, creme de leite e leite condensado) nas prateleiras dos mercados ludovicenses e similares. 


\section{Mapeamento das variáveis e aquisição de amostras}

A segunda fase consistiu na identificação dos produtos vendidos por cada marca, apresentando também suas subcategorias, mostrando assim o que cada fabricante disponibiliza para o consumidor.

\section{Coleta de cores}

A terceira fase coletou as cores das amostras devidamente identificadas e separadas. Utilizouse um mini Studio marca Puluz em forma de cubo com $25 \mathrm{~cm}$ de altura, com iluminantes de 40 LEDs de 6500k em duas linhas e abertura no topo por onde um smartphone Apple, modelo XR, realizou a captura das imagens. Em seguida, as imagens resultantes tiveram sua cor RGB coletada através da ferramenta Conta-gotas do software Adobe Illustrator 2020, servindo de referência para as análises de dados.

\section{Perfil de cores}

A quarta e última fase apresentou o padrão de cores das embalagens avaliadas, organizadas por cores principal e secundária de cada tipo de produto e subcategoria. As principais ocorrências resultam no perfil cromático de cada tipo de produto.

\section{Resultados}

Após a identificação das marcas dos fabricantes, efetuou-se o mapeamento dos produtos vendidos em mercados e similares na cidade de São Luís. O quadro 1 apresenta as quatro marcas, frutos destes cruzamentos de dados e suas categorias, como as três variações dos produtos (integrado, semidesnatado e desnatado) e os quatro tipos diferentes de produtos (leite líquido, leite condensado, creme de leite e leite em pó).

Quadro 1: Apresentação dos produtos investigados, divididos por marcas e variações

\begin{tabular}{llllll}
\hline Marca & Variação & $\begin{array}{l}\text { Leite } \\
\text { em pó }\end{array}$ & $\begin{array}{l}\text { Leite } \\
\text { líquido }\end{array}$ & $\begin{array}{l}\text { Leite } \\
\text { condensado }\end{array}$ & $\begin{array}{l}\text { Creme } \\
\text { de leite }\end{array}$ \\
\hline Nestlé & $\begin{array}{l}\text { Integral } \\
\text { Semidesnatado }\end{array}$ & $\mathrm{X}$ & $\mathrm{X}$ & $\mathrm{X}$ & $\mathrm{X}$ \\
& $\begin{array}{l}\text { Desnatado } \\
\text { Piracanjuba }\end{array}$ & & & & \\
& $\begin{array}{l}\text { Integral } \\
\text { Semidesnatado }\end{array}$ & $\mathrm{X}$ & $\mathrm{X}$ & & $\mathrm{X}$ \\
& $\begin{array}{l}\text { Desnatado } \\
\text { Camponesa }\end{array}$ & & & $\mathrm{X}$ & \\
& $\begin{array}{l}\text { Integral } \\
\text { Semidesnatado }\end{array}$ & $\mathrm{X}$ & & $\mathrm{X}$ & $\mathrm{X}$ \\
& Desnatado & & & & \\
\hline
\end{tabular}




\begin{tabular}{llll}
\hline CCGL & Integral & $X$ & $X$ \\
& Semidesnatado & & \\
& Desnatado & & \\
\hline
\end{tabular}

A partir dessa categorização, passou-se para a etapa de coleta de cores. Para melhor entendimento dos resultados coletados, optou-se por descrevê-los conforme os quatro produtos estudados.

\section{Leite em pó}

As 4 marcas investigadas apresentam produtos de variação integral, como apresenta a figura 2.

Figura 2 - amostras das embalagens de leite em pó, com as principais ocorrências de cores.
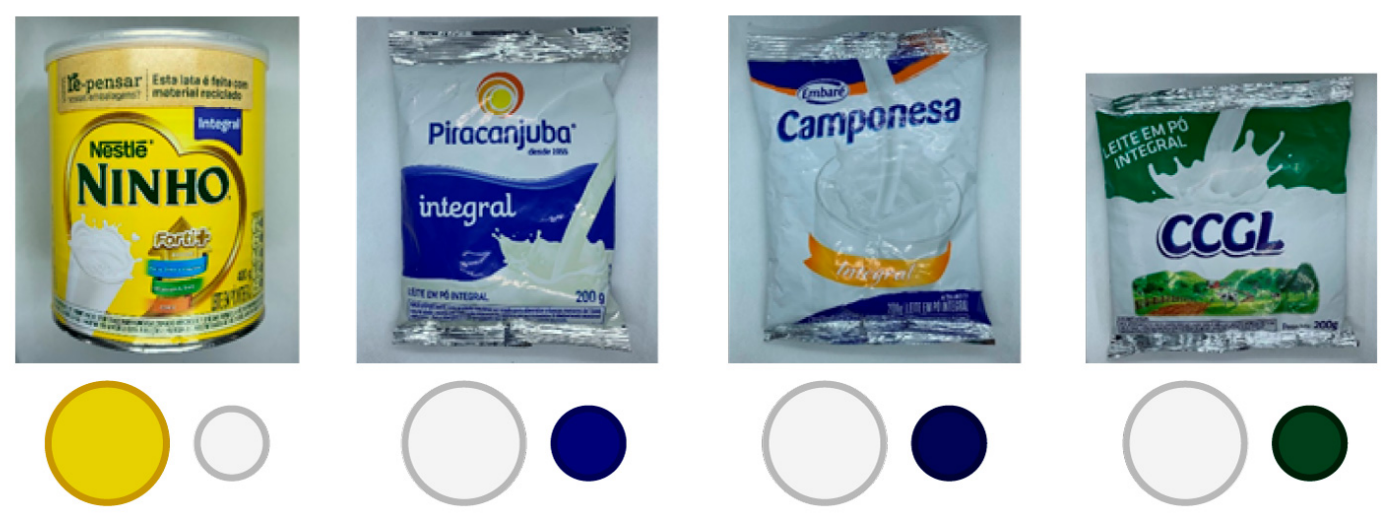

Ao atentar-se para o espaço em que as cores preenchem em suas estampas, certamente ter-se-iam por cores principais o branco e o amarelo. No entanto, o parâmetro da avaliação não foca na ocorrência isolada em um produto, mas não leva em consideração a ocorrência desse matiz nas quatro amostras. 
Figura 3 - percentual de cores das amostras das embalagens de leite em pó.

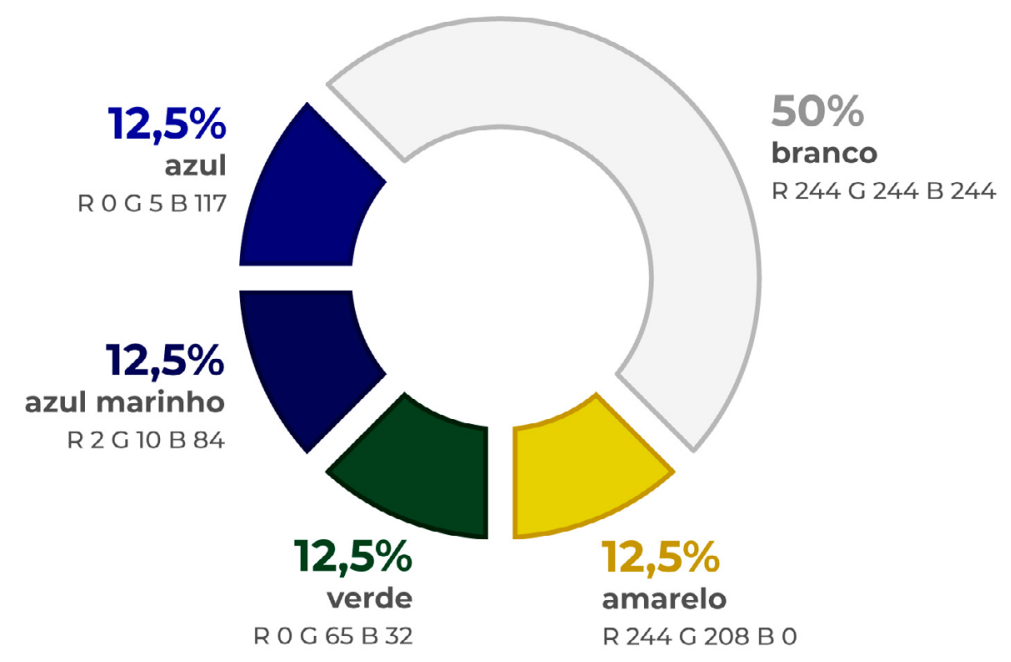

No entanto, a captura das cores e dos valores RGB (recurso usado para auxiliar na distinção de nuances das cores), vistas na figura 3 , apresentam uma distribuição diferente a essa observação, apresentando cinco tons diversos.

Vê-se o branco mantendo-se como tom dominante, aponta $50 \%$ das ocorrências. É percebida tanto como cor principal em três amostras, como também secundária em uma delas. Foi percebida de maneira igualitária de tons de azul (azul e azul marinho), que somam 25\% das cores coletadas. Os demais tons, não menos importantes, como amarelo e verde, pontuam $12,5 \%$ cada um.

\section{Leite líquido}

Dentre as quatro marcas avaliadas neste artigo, apenas duas apresentam exemplares de leite líquido disponíveis nas prateleiras. A figura 4 mostra que, além disso, as amostras encontradas são da subdivisão integral.

Figura 4 - amostras das embalagens de leite líquido com as principais ocorrências de cores.
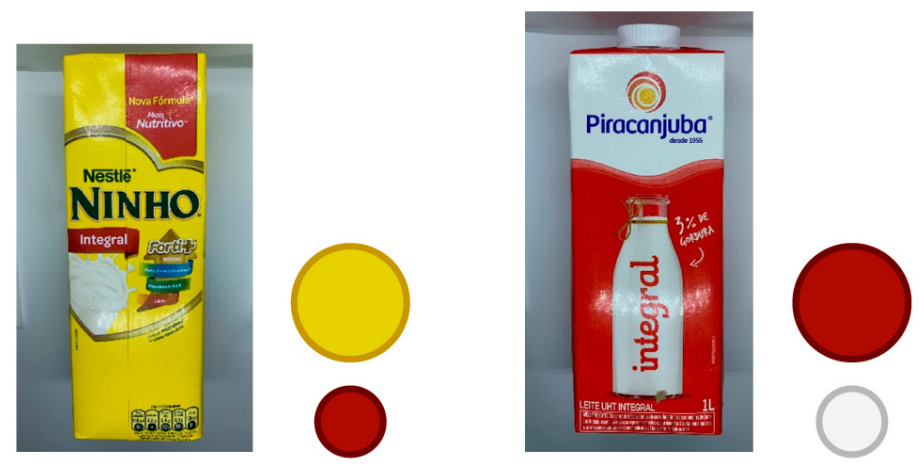
As imagens dos produtos capturas mostram a predominância de três cores: amarelo, branco e vermelho. É interessante ressalta que as duas últimas estão presentes em proporções diversas nas duas amostras coletadas. Ao observar a figura 4, pode-se proferir que as cores principais são o amarelo e o vermelho, bem como as secundárias são o branco e o vermelho. Como já mencionado, o que se verifica neste trabalho não apenas o espaço em si em que a cor "preenche" no substrato da embalagem, mas também o quanto estes matizes aparecem nestas interfaces.

Figura 5 - percentual de cores das amostras das embalagens de leite líquido.

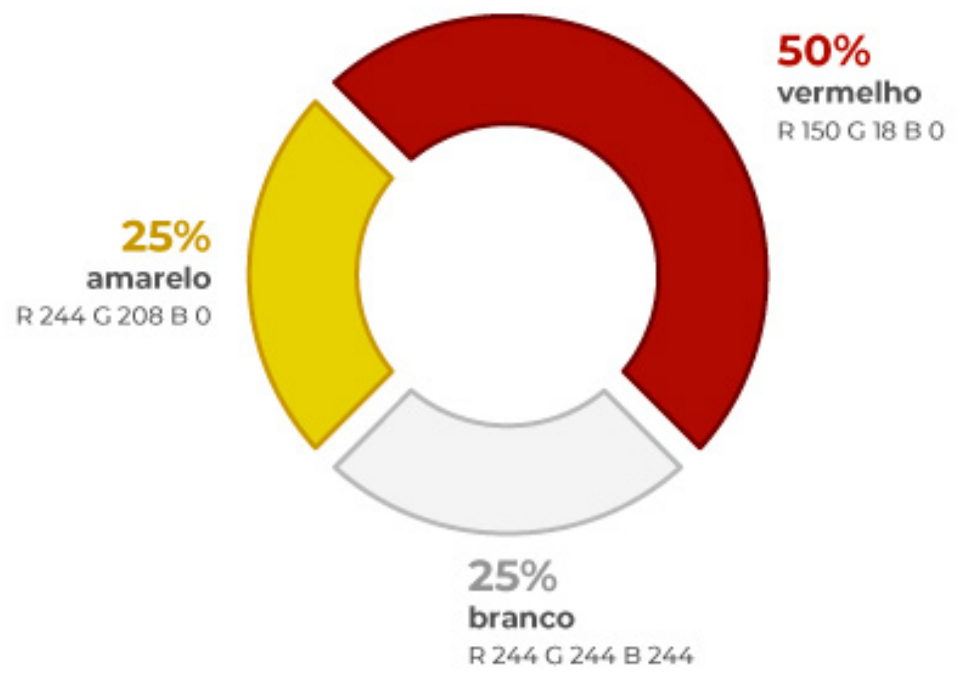

Dessa forma, entende-se que o vermelho, tal qual aponta a figura 5, é a principal ocorrência entre as embalagens de leite líquido, com $50 \%$ dos resultados obtidos. Conforme mencionado, tal tom ocupa como cor principal em uma das embalagens e secundária em outra. Empatando em ocorrências, estão o amarelo e o branco, ambas com $25 \%$. A primeira cor, já até comentada, é da mesma marca da embalagem em amarelo de leite em pó. Essa "desviopadrão" percebido nos dois tipos de leite para essa marca reforça a ideia da necessidade de diferenciação em relação às demais que usam o branco como ou cor-base ou uma das cores de sua paleta.

\section{Leite condensado}

Observou-se, como aponta a figura 6 , a respeito dos exemplares de leite condensado que dentre as quatro marcas estudadas, três apresentam produtos, onde dois deles são classificados como integral e um como semidesnatado. 
Figura 6 - amostras das embalagens de leite condensado com as principais ocorrências de cores.
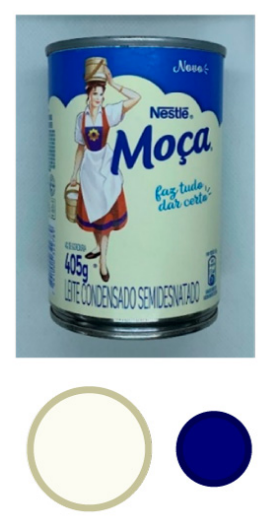
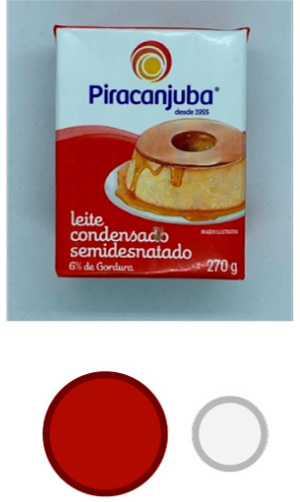
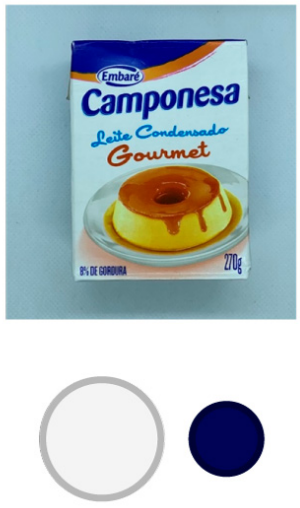

Como vê-se na figura 6 , percebe-se a forte presença de cores claras nas três embalagens, onde em duas o branco é notado (principal em um e secundária em outra) e na terceira vê-se uma significativa tonalidade de bege, como cor principal. Esse segundo tom claro provavelmente remete o observador a uma referência mais antiga, saudosista, dada a configuração mais tradicional da ilustração da embalagem.

Esses tons pontuam juntos a metade (50\%) das ocorrências, onde o branco marca um terço do total das cores avaliadas $(33,33 \%)$, como mostra a figura 7.

Figura 7 - percentual de cores das amostras das embalagens de leite condensado.

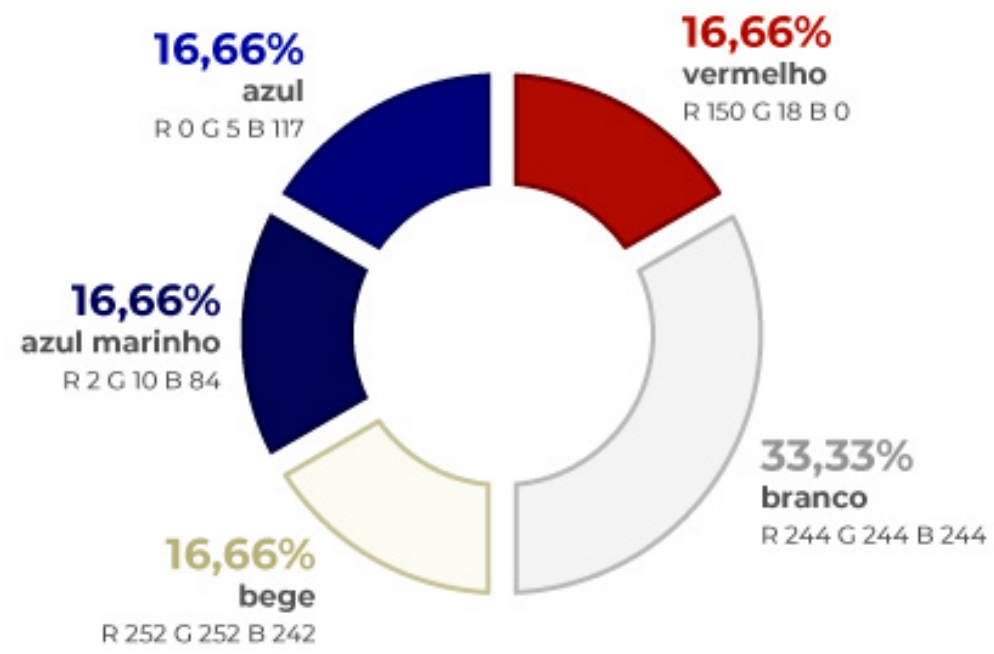

É interessante ressaltar a presença dos dois tons de azuis, totalizando também um terço de todas as ocorrências, como na figura 7. Como contraponto, percebe-se a notória presença do vermelho $(16,66 \%)$, dada as devidas proporções das dimensões das embalagens, é vista da mesma forma no projeto gráfico de caixa de leite líquido da mesma marca. 


\section{Creme de leite}

Quanto ao creme de leite, a figura 8 ilustra que todas as quatro marcas analisadas, enquadradas como integral, possuem cada qual um representante.

Figura 8 - amostras das embalagens de creme de leite com as principais ocorrências de cores.
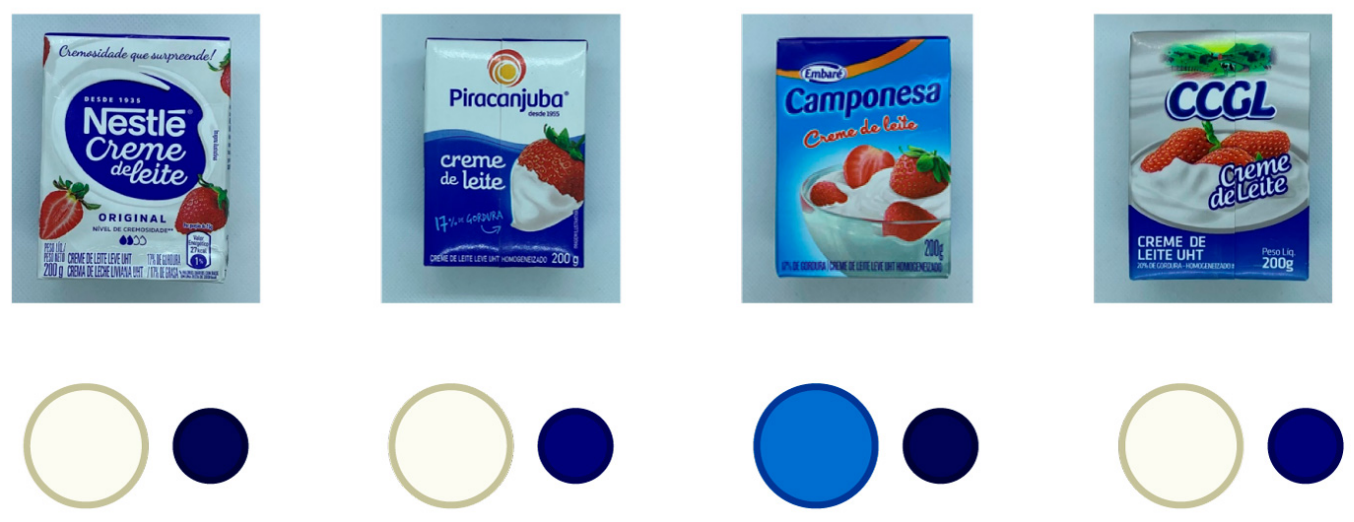

Observaram-se em todas as amostras que o branco é a cor principal, proporcionalmente $37,5 \%$ das ocorrências, como quer a figura 9 .

Figura 9 - percentual de cores das amostras das embalagens de creme de leite.

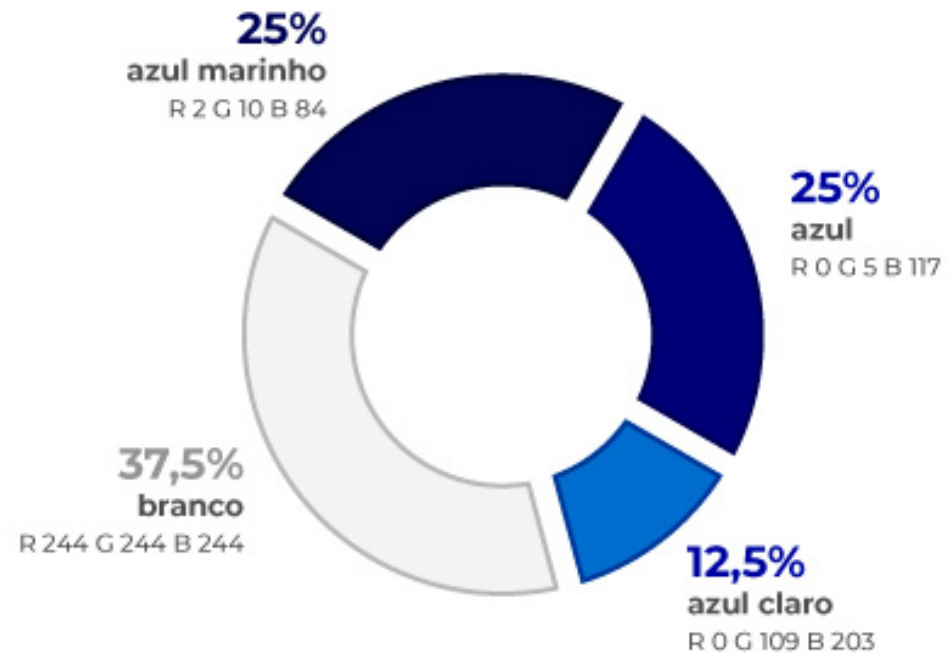

É interessante também apresentar que, além da diagramação de elementos textuais, formas geométricas e ilustrações, há também três variantes de azul (aqui convencionados como claro, "normal" e marinho"), desprezando degradês e efeitos de ilustração. Os três juntos somam $62,5 \%$ das cores avaliadas, destacando-se os tons de azul e de azul marinho que igualmente marcam $25 \%$. Sobre a presença dessa variedade de azuis. 


\section{Discussões}

Após a amostragem dos resultados coletados, descreve-se aqui a fase discursiva com a abordagem teórica dos fenômenos encontrados.

\section{Leite em pó}

A primeira série apresenta a paleta cromática mais diferente das quatros séries estudadas. O branco é a principal ocorrência percebida. Para Zylbergleid (2017, p. 54), tal cor, encontrada não só neste tipo de leite como nos outros derivados, é uma forte característica nos embrulhos de leite líquido, pois, além de estar associado a alimentos, representa a matéria-prima do produto: o leite. Ademais, remete à paz, calmaria, a pureza que o produto precisa informar $\mathrm{e}$, sobretudo, os aspectos de higiene e limpeza, como complementa Heller (2013). Quanto ao design, Pereira (2011) apresenta esta cor, utilizada como fundo, como importante para a organização e composição de informações, imagens e outros elementos visuais. Mesmo não tendo o "toque" de vermelho como Mestriner (2005) recomenda, ele sugere a presença de vários tons de azul. Estes azuis estão presentes de forma diversa em todas as amostras, desde um pequeno box que destaca uma informação até a "competir" (melhor dizer contrastar) com o branco já comentado. Apesar de estar como cor secundário nesse produto, complementa-se ao branco, assim como o azul das demais séries, as sensações de confiabilidade, tranquilidade, higiene que uma empresas de laticínios busca para suas embalagens (Zylbergleid, 2017).

Sobre o amarelo, Heller (2013) o aponta como a mais ambígua das cores, porque pode transmitir diversos sentimentos, dependendo da cor que está associada. Zylbergleid (2017) associa ao amarelo com o estímulo ao apetite, recomendando-o na promoção de restaurantes e produtos alimentícios. Ao tratar-se dessa cor no contexto das embalagens de produtos alimentícios, Pereira (2011) a aponta como um matiz associado em $44,7 \%$ das ocorrências a alimentos dessa tonalidade (milho, maracujá, laranja, mostarda, margarina, queijo), como também traz valores como energia (16,5\%) e diversão e infância (10,6\%). Ainda a respeito do amarelo, Ambrose e Gavin (2009) o apontam sua versatilidade na representação de vários estados emocionais e, no contexto do design, salientam sua combinação com o preto como de alto contraste, sinalizando advertência, portanto visibilidade.

O verde é, na visão de Mitsuyasu (2013), visto como a cor oficial da saúde, uma vez que denota frescor, natureza, conferindo um diferencial para a marca que a adota em sua embalagem. Também traz consigo os sentimentos de permissão, de segurança, assim consolidado em muitos países um compartilhamento dos significados dos padrões das cores dos semáforos (verde - siga, amarelo - atenção, vermelho - pare) com o sistema de identificação das embalagens de produtos, como nos produtos da britânica Food Standards Agency, que apresenta círculos verdes, amarelos e vermelhos para sinalizar relativamente saudável, níveis intermediários e não saudáveis de nutrientes, respectivamente. (Pereira, 2011; Schuldt, 2015; Vasiljevic et al., 2015). Em relação às atuais questões sanitárias, Pastoureau e Simonnet (2008) apontam essa cor, junto com o branco, como a mais higiênica. Esse mesmo verde alude ao natural, cor da vegetação e, quando empregados no design dos produtos, 
aponta que estes possuem em todo o seu processo princípios sustentáveis (minimização de impactos ambientais tanto do produto, quanto da embalagem), como também uma tendência dos consumidores de associar tal cor a alimentos mais naturais, orgânicos ou com menos calorias (Schuldt, 2013).

\section{Leite líquido}

A respeito das ocorrências do leite líquido, cabe comentar acerca da principal ocorrência: o vermelho. Zylbergleid (2017) comenta sobre a grande intensidade desse matiz, tratando-a como atrativa, chamativa e positiva para produtos de prateleira, como destaque e alerta. Farina (1983) destaca o vermelho como um tom estimulante ao apetite, além de lúdica, também é associada por crianças ao doce, o que favorece o consumo do produto. Pereira (2011) trata o vermelho como uma cor comum do setor de embalagens de alimentos, como em frutos e carnes, representativa do ingrediente ou do próprio produto. Ademais, traduz propriedades integrais e objetivas do produto embalado (integral) e conceitos e valores de marca (tradicionalismo, energia, amor, paixão). Assim, pode-se dizer que o vermelho, quando aplicada à embalagem, chama atenção, principalmente em produtos alimentícios. Dentro do design, direciona a atenção do usuário a algo específico do projeto, como uma informação importante ou destaque. No entanto, Ambrose e Gavin (2009) sugerem que haja moderação em seu uso evitando aplicá-la em grandes blocos de textos sobre fundo branco, por tal modo ser cansativo para o leitor, não sendo uma experiência positiva, já que o vermelho não é um matiz relaxante.

Simultaneamente, tem seu público-alvo (principalmente o infantil) representado pela ludicidade que Zylbergleid (2017) aponta para o amarelo, que provoca sentimentos alegres e animados. Também é "chamativo, berrante, como a cor da advertência" (Heller, 2013, p. 15). Por fim, o uso de amarelo como fundo tem resultados favoráveis, onde Farina, Perez \& Bastos (2006) recomendam tal uso por ser fácil a memorização, se comparado com o fundo azul.

Já o branco, "[...] a cor do leite, da neve, indicia neutralidade, pureza, vida quando associada à alimentação (leite), limpeza, castidade, liberdade, criatividade" (Farina, Perez \& Bastos, 2006), apresenta-se como elemento de contraste, sobretudo ao lado do vermelho, tanto para destacar a presença do produto em ilustração, como para destacar a marca no projeto gráfico. Esse tipo de alerta e destaque, contudo, é até visualizado como proibição e perigo na natureza. Apesar disso, Pereira (2011) defende tal tom como estimulante em termos psicofisiológicos e culturais, pois, apresenta-se como fundamental para a sobrevivência e as relações humanas, sendo, na visão de Pastoureau (1993), sinônimo da palavra "colorido" em alguns idiomas.

E, quando combinado com o amarelo, Heller (2013) confirma que causa o efeito visualmente mais leve dentre todas as combinações. Além disso, quando usado como cor de fundo favorece atenção dispensada por parte dos usuários por conta do contraste promovido por este matiz, contraste este que afeta de forma relevante na forma deles percebem os 
atributos dos produtos (qualidade, apelo visual e intenção de compra) (Bix., Seo \& Sundar, 2013).

\section{Leite condensado}

O terceiro tipo de produto estudado apresenta o branco como um terço das ocorrências e as demais cores ( 2 tons de azuis, bege e vermelho) na mesma proporção, como cores coletadas.

A respeito desse fenômeno, Pereira (2011) apresenta o branco parâmetro visual para que o valor de todas as demais cores possa ser percebido. Certamente, a sensação de clareza visual e modernidade também defendidas pela autora ajudam na compreensão clara das informações presentes na embalagem. Isso vai de acordo com o discurso de Heller (2013) acerca de essa cor ser a "mais perfeita", se tratando dos aspectos simbólicos; além da preferência com tom principal no design minimalista, evocando a atenção à funcionalidade. Ademais, essa "brancura imaculável" que Forty (2007) ressalta a imagem de higiene e associação à saúde.

A opção por essa cor nesse terceiro tipo de produto lácteo, como no primeiro, reforça ainda mais a ideia acerca o contraste de informação com o branco (e aqui o bege), além da confiança e harmonia (Heller, 2013).

Sobre o matiz azul, Ambrose e Gavin (2009) relatam que suas variações mais escuras denotam conservadorismo no mundo corporativo, por significar estabilidade, segurança e confiança. Já sobre os tons mais claros, eles ressaltam predicados mais serenos e jovens.

Para este caso, pode-se supor que seja um padrão cromático adotado pela empresa para sua linha de produtos, onde o "carro-chefe" de cada tipo de produtos tem o vermelho, já discutido como chamativo e cor de destaque, busca a diferenciação dentre os concorrentes nas prateleiras. As cores quentes, como o vermelho, são associadas a atributos hedônicos e estimulam a vinculação ao sabor doce (Walsh et al., 1990; Raghunathan, Naylor., \& Hoyer, 2006).

A literatura também aponta apontam a relação da cor verde em embalagens e rótulos de produtos de alimentos mais saudáveis e a aplicação do vermelho em rótulos para opções não consideradas saudáveis (Schuldt, 2013; Huang \& Lu, 2015; Vasiljevic, Pechey \& Marteau, 2015).

Mas, para ter-se maior certificação sobre esta questão, faz-se necessária uma investigação mais aprofundada sobre a linha completa dos produtos da marca em questão que, neste artigo, não estão presentes por conta da indisponibilidade destes nos mercados da cidade.

\section{Creme de leite}

A quarta série apresenta uma interessante combinação de 3 tons de azuis e branco como leque de cores.

Assim, o creme de leite mostra, por suas cores, como as marcas promovem os sentimentos não só de pureza e limpeza já expressa pela alvura do branco, ou apenas pela confiança que o azul passa. Mas, entendem que a relação entre o azul e o branco passam honestidade, nobreza e verdade (Heller, 2013). E essa honestidade e verdade trabalhadas são vistas na 
visualização do produto em uso (branco), com fundos em contraste (preto, laranja e azul, por exemplo), assim como sua predominância no layout (grande quantidade de espaço em branco) adiciona requinte e solidez ao design apresentado (Ambrose \& Gavin, 2009).

Repara-se, mesmo que não tenha sido apontada como cor secundária, a presença do morango (representando o vermelho como cor) em todas os quatro exemplares. A preferência por essa fruta, certamente associada a esse tipo de produto, também reforça o contraste na embalagem, "[...] uma vez que o efeito do contraste de cor opera na direção da complementaridade fisiológica, ele serve para aumentá-la [...]" (Arsmein, 2005, p. 352).

Heller (2013) afirma que o azul é a cor predileta por $46 \%$ dos homens e $44 \%$ das mulheres, usual em vários produtos, como carros e roupas (jeans); alegando a existência de 111 tons e ainda aponta como uma cor feminina, retratada em obras religiosas com imagens de Nossa Senhora. A cor é vista como um dos recursos de design de embalagem mais eficazes na indústria de alimentos, tanto os consumidores quanto os fabricantes costumam associar alimentos saudáveis e nutritivos a embalagens verdes ou azuis (Huang \& Lu, 2015).

Certamente, por coincidência ou por estudo (não cabe avaliar neste trabalho), o público-alvo que consome creme de leite é predominantemente feminino. E essa quantidade de tons de azuis, semelhantes entre si, tratado por Mitsuyasu (2013) como análogas por serem cores próximas umas das outras e apresentarem opções de harmonização. O emprego desse matiz em embalagens de produtos se relaciona com aspectos informacionais sobre o alimento embalado, sabores e variedades, identificação de categorias e tipos de processos e consumos do produto (Pereira, 2011).

\section{Perfil resultante das embalagens estudadas}

A partir da avaliação setorial, em cada tipo de produto, reuniram-se os resultados dos 13 exemplares das 4 marcas estudadas apontadas pela Embrapa (2019) como as mais vendidas no país e presentes nas prateleiras de três supermercados atuantes na cidade de São Luís (Nestlé, Piracanjuba, Camponesa e CCGL).

Como foram observadas em cada série de produtos a ocorrência de 2 cores - uma principal e outra secundária, logo, o perfil resultante de todo o estudo é fruto da reunião das 26 cores avaliadas e seus respectivos índices em percentuais apresentados na figura 10. 
Figura 10 - perfil cromático resultante da análise das cores das embalagens estudadas.

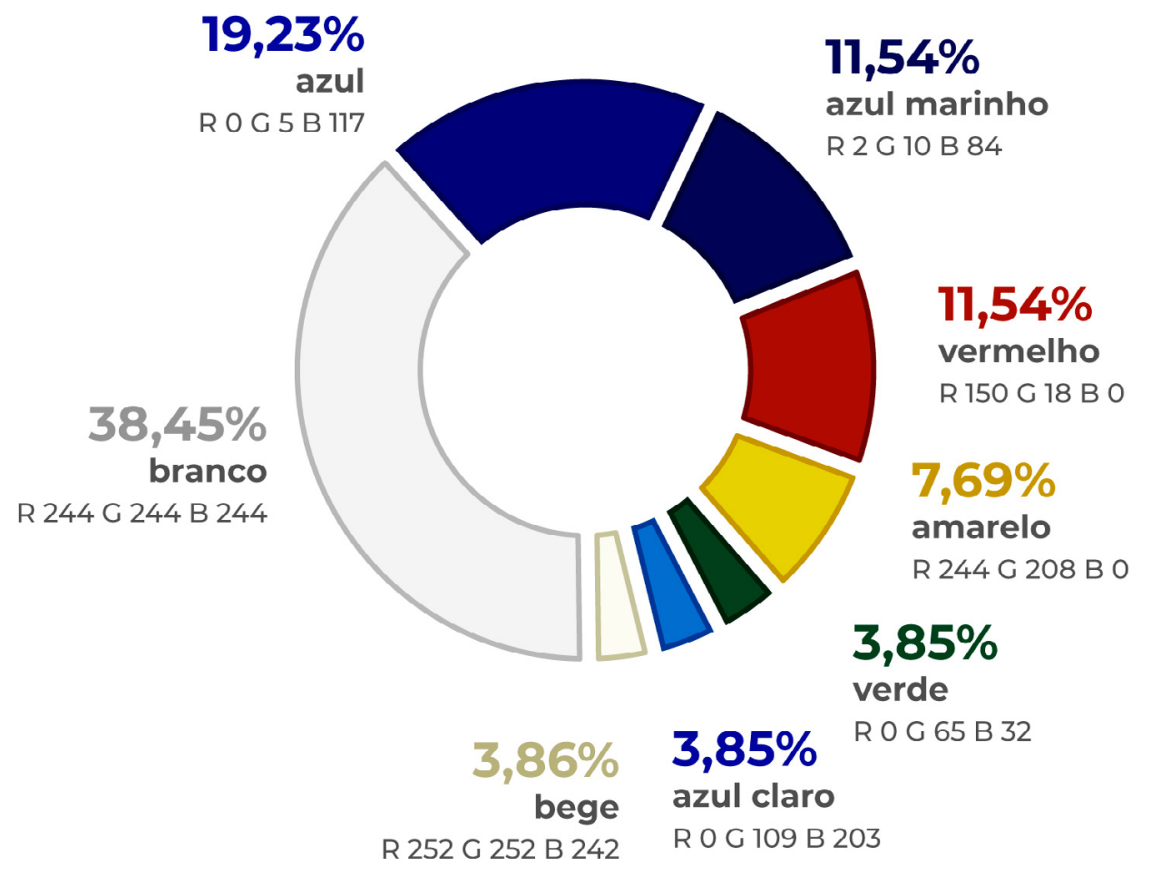

O branco é a cor com maior valor (38,45\%), o que já era esperado. Afinal, é a cor do leite, como lembra Heller (2013), o primeiro alimento que o homem recebe. Pereira (2011) adverte que a preferência por tal cor, aponta por ele como a ausência de cor em meio à saturação cromática do ambiente visual das prateleiras de supermercado, como a que cumpre com o papel funcional de chamar mais a atenção do consumidor (função que as demais cores foram perdendo com o tempo). O clareamento químico de alimentos, como a farinha refinada, explica e reafirma como o branco é fortemente percebido como sinônimo de pureza, apesar das perdas de nutrientes com o processo de alvura (Pereira, 2011). Essa oposição à contaminação por micro-organismos e presença de sujeira no contexto alimentar que tal cor promove é também advertida por Bobrow-Strain (2005), quando disserta sobre a brancura do pão consumido na Europa e nos Estados Unidos, uma vez que tal condição permitia a constante verificação das condições das superfícies deste e de alimentos similares.

. O azul e seus 3 tons, somam $34,62 \%$. Esta cor remete à segurança, credibilidade e confiança - requisitos necessários para um produto lácteo e sua embalagem. Sendo uma cor fria, também relembra a forma como o alimento deve ser conservado após aberto para consumo em ambiente refrigerado (Heller, 2013). Já Huang \& Lu (2015) exemplificam o uso do verde em embalagens de leite da marca Upstate Farms para leite com $1 \%$ de teor de gordura e o azul para caixas de leite desnatado. Os autores justificam que tais cores sinalizam alimentos saudáveis, pautando-se nas profundas e enraizadas reações psicológicas dos consumidores a estas cores, havendo reforço do ambiente sociocultural onde estão inseridos.

Essas duas cores pontuam juntas 73,08\%, justificando o pensamento de Pedrosa (2010) que aponta tais tons como dominantes e que detêm maior parte do gráfico cromático, 
aparecendo como primárias e secundárias em quase todas as paletas de cores das embalagens. E Heller (2013, p. 57) reforça tal fenômeno verificado ao dizer que "o leite e os laticínios em geral são embalados em azul e branco". O azul também se relaciona à restrição nutricional e/ou redução de componentes dos tipos de alimentos, já que $27,7 \%$ das embalagens avaliadas por Pereira (2011) são de produtos identificados como "light", "semidesnatado", "zero", "descafeinado", "desnatado" ou "água e sal"; conferindo uma proposta que se diferencia das versões originais. A pesquisadora também se observou que $17,7 \%$ das embalagens azuis remetem a produtos de origem láctea, sendo (junto com o branco) uma cor característica deste tipo de produto e de marcas do ramo (apesar das variedades de produtos disponíveis). No mesmo estudo, o azul denota qualidade superior (linha "prime" ou "premium"), apontando características "especiais" em 12,3\% das embalagens apresentadas.

Os demais tons, como vermelho $(11,54 \%)$, amarelo $(7,69 \%)$, verde $(3,85 \%)$ e bege $(3,85 \%)$ tiveram suas ocorrências como elementos de fundo gráfico ou como forma geométrica de destaque na ilustração, mas com pouca frequência nos quatro tipos de produtos. Foram cores que aparecem de maneira mais específica, como o amarelo que a marca Nestlé como fundo em dois produtos com uma marca específica (Ninho) e adotou o verde como cor secundária para trazer contraste para a leitura das informações.

Como já mencionado, é interessante falar a relação que os consumidores fazem entre as cores e as qualidades dos alimentos, como serem mais saudáveis e naturais (azul e verde) ou mais saborosos (vermelho) (Harper \& Makatouni, 2002; Kaya \& Epps, 2004; Hughner et al., 2007; Clarke \& Costall, 2008; Huang \& Lu, 2015; Vasiljevic, Pechey \& Marteau, 2015).

Observando os tipos de alimentos aqui estudados, supõe-se que houve por parte dos fabricantes a opção por cores mais frias, visando enaltecer a qualidade e a saudabilidade do produto. Assim, justifica-se também a menor ocorrência de cores quentes como principais que, pois, nestes casos serviram como matizes de destaque e definição de uma linha que não tenha redução de elementos de sua composição nutricional (não enveredando pela conotação gustativa).

\section{Considerações Finais}

De fato, a embalagem apresenta o artefato. E por meio desse artigo foi possível constatar as ocorrências cromáticas, suas semelhanças e diferenças, coisa que reflete a idealização da marca, seus valores e conceitos.

Os treze tipos de amostras diferentes apresentaram cada qual uma cor primária e outra secundária, obtendo-se uma paleta de vinte e seis tons diversos. Nesse universo de cores apontados por embrulhos de leite em pó, leite líquido, leite condensado e creme de leite, percebeu-se a notória presença da cor branca $(38,46 \%)$ e da cor azul em suas variações $(34,62 \%)$. Estes dois padrões apresentaram-se repetidas vezes neste estudo, estando presentes nos quatro tipos de produtos investigados (com exceção em leite líquido que apenas o branco esteve presente). Esse padrão encontrado é confirmado pela literatura como suporte de cor mais representativo para embalagens de lácteos. Todavia, vê-se em alguns momentos, 
algumas embalagens apresentando um leque cromático com tons diferentes, como vermelho, amarelo e verde, o que propõe a reflexão acerca da diferenciação destes produtos nas prateleiras, tendo em vista o poder que as cores têm sobre a decisão de compra.

A verificação destes fenômenos são contributos para o Design da Informação não apenas como discussão e conteúdo teórico, assim como conhecimento auxiliador no desenvolvimento de embalagens de produtos lácteos; já que a cor, como já visto, é além de um fator informativo do produto, é um elemento significativo na decisão de compra.

Assim, por este estudo ser apenas preliminar, carecendo de mais outras pesquisas para maior aprofundamento dele, como sugestão para estudos futuros cabe a investigação aprofundada sobre esse leque cromático diverso não apenas com as marcas e produtos estudados, como também ampliar a quantidade de marcas que atuam não só na cidade de São Luís, como também em nível nacional. Também cabe como proposta o estudo mais aprofundado por tipos de produtos, tendo como variáveis suas subdivisões, visando riquezas e precisão de informações maiores.

\section{Referências Bibliográficas}

Ambrose, G. \& Harris, P. (2009) Design Básico Cor. (trad) Francisco Araújo da Costa. Porto Alegre: Bookman.

Arsmein, R. (2005). Percepção Virtual: Uma psicologia da Visão Criadora: 1.ed. Câmara Brasileira de Livros.

Battistela, N., Colombo, J. R. \& Abreu, K. C. K. (2010). A Importância da Cor nas Embalagens como Fator Influenciador no Momento da Compra. Biblioteca on-line de Ciências da Comunicação.

Baxter, M. (2011). Projeto de produto: Guia prático para o design de novos produtos. 3a ed. São Paulo: Blucher.

Benevides, I. A. \& Veiga, A. (2014). Aspectos históricos, fisiológicos e antroposóficos do leite na alimentação humana: uma introdução ao tema. Arte Médica Ampliada. Vol. 34 | N. 1.

Bix, L., Seo, W., \& Sundar, R. P. (2013). The Effect of Colour Contrast on Consumers' Attentive Behaviours and Perception of Fresh Produce. In: Packaging technology and science, 26, 96 -104 .

Bobrow-Strain, A. Since Sliced Bread: Purity, Hygiene, and the Making of Modern Bread. Science, Culture and the Making of Modern Food: Annual Meetings of the Association of American Geographers, 2005.

Chiachiri, R. (2011). O Poder Sugestivo da Publicidade: uma Análise Semiótica. São Paulo, Editora Cengage Learning.

Clarke, T., \& Costall, A. (2008). The emotional connotations of color: A qualitative investigation. In: Color Research \& Application, 33(5), 406-410.

Deliza, R., Macfie, H. A. L., \& Hedderley, D. (2003). Use of computer-generated images and conjoint analysis to investigate sensory expectations. In: Journal of Sensory Studies, 18 (6), 465-486.

Empresa Brasileira de Pesquisa Agropecuária (2019). Anuário leite. São Paulo. 
Farina, M., Perez, C. \& Bastos, D. (2006). Psicodinâmica das cores em comunicação. $5^{\mathrm{a}}$ ed. São Paulo: Edgard Blücher.

Forty, A. Objetos de desejo: design e sociedade desde 1750. São Paulo: Cosac Naify, 2007.

Harper, G. C., \& Makatouni, A. (2002). Consumer perception of organic food production and farm animal welfare. In: British Food Journal, 104(3/4/5), 287-299.

Heller, E. (2013). A psicologia das cores: como as cores afetam a emoção e a razão. 1 ed. São Paulo: Gustavo Gili.,

Huang, Lei; Lu, Ji. Eat with Your Eyes: Package Color Influences the Perceptions of Food Taste and Healthiness Moderated by External Eating. In: Marketing Management Journal, Fall 2015.

Kauppinen-Räisänen, H. (2014). Strategic Use of Colour in Brand Packaging. In: Packaging Techonology and Science, 27: 663-676.

Kaya, N., \& Epps, H. H. (2004). Relationship between color and emotion: A study of college students. In: College Student Journal, 38 (3), 396-406.

Jung, C. F. \& Matte Júnior, A. A. (2017). Produção leiteira no Brasil e características da bovinocultura leiteira no Rio Grande do Sul. Ágora. Santa Cruz do Sul, v.19, n. 01, p. 34-47.

Mestriner, F. (2005). Design de Embalagem. 2.ed. São Paulo: Pearson Prentice Hall.

Mitsuyasu, M. K. (2013). Método de análise paramétrica do design: Modelo Fuzzy para avaliação de produtos. 242f. Tese (doutorado) - Universidade Federal do Rio de Janeiro, COPPE, Programa de Engenharia de Produção.

Mohebbi, B. (2014). The art of packaging: An investigation into the role of color in packaging, marketing, and branding. In: International Journal of Organizational Leadership, 3, 92-102.

Pastoureau, M. Dicionário das cores do nosso tempo: simbólica e sociedade. (trad.) Maria José Figueiredo. Lisboa: Editorial Estampa, 1993.

Pastoureau, M.; e Simonnet, D. Couleurs: le grand livre. Paris: Éditions du Panama, 2008.

Pedrosa, I. (2010). Da cor à cor inexistente. Rio de Janeiro: SENAC Nacional.

Pereira, C. P. A. (2011). A cor como espelho da sociedade e da cultura: um estudo do sistema cromático do design de embalagens de alimentos. 257 p. Tese (Doutorado em Design e Arquitetura). Faculdade de Arquitetura e Design - Universidade de São Paulo.

Raghunathan, R., Naylor, R. W., \& Hoyer, W. D. (2006). The unhealthy = tasty intuition and its effects on taste inferences, enjoyment, and choice of food products. In: Journal of Marketing, 70(4), 170-184.

SBAN - Sociedade Brasileira de Alimentação e Nutrição. (2015). A importância do consumo de leite no atual cenário nutricional brasileiro. São Paulo: [s.l.].

Schuldt, J. P. (2013). Does green mean healthy? Nutrition label color affects perceptions of healthfulness. In: Health Communication, 28(8), 814-821.

Sousa, M. M. M.; Carvalho, F. B.; Pereira, R. G. F. A. (2020). Colour and shape of design elements of the packaging labels influence consumer expectations and hedonic judgments of specialty co $\square$ ee. In: Food Quality and Preference, 83, 103902. 
Vasiljevic, M., Pechey, R., \& Marteau, T. M. (2015). Making food labels social: The impact of colour of nutritional labels and injunctive norms on perceptions and choice of snack foods. In: Appetite, 91(1), 56-63.

Vilela, D., Ferreira, R. P., Fernandes, E. N. \& Juntolli, F. V. (2016). Pecuária de Leite no Brasil Cenários e avanços tecnológicos. Brasília: Embrapa.

Walsh, L. M., Toma, R. B., Tuveson, R. V., \& Sondhi, L. (1990). Color preference and food choice among children. In: The Journal of Psychology, 124(6), 645-653.

Zylbergleid, F. (2017) A influência das cores nas decisões do consumidores. Monografia (graduação) Universidade Federal do Rio de Janeiro, Escola Politécnica/ Curso de Engenharia de Produção, Rio de Janeiro.

\section{Sobre o(a/s) autor(a/es)}

David Guilhon, Me., Universidade Ceuma, Brasil <david.guilhon@ceuma.br>

Erika Veras de Castro, Me., Universidade Ceuma, Brasil <erika.castro@ceuma.br>

Viviane Pranto da Silva, Bac., Universidade Ceuma, Brasil <vivianepranto@gmail.com> 